International Journal of Automotive and Mechanical Engineering (IJAME)

ISSN: 2229-8649 (Print); ISSN: 2180-1606 (Online); Volume 6, pp. 692-700, July-December 2012

(OUniversiti Malaysia Pahang

DOI: http://dx.doi.org/10.15282/ijame.6.2012.2.0056

\title{
Cr-Ni ALLOY ELECTRODEPOSITION AND COMPARISON WITH CONVENTIONAL PURE Cr COATING TECHNIQUE
}

\author{
M. Moniruzzaman, M.M. Rakib and F.T. Matin \\ Department of Materials and Metallurgical Engineering \\ Bangladesh University of Engineering and Technology (BUET) \\ Dhaka-1000, Bangladesh \\ E-mail: mmoniruzzaman@mme.buet.ac.bd
}

\begin{abstract}
Cr coating is widely used as the outer surface of precision parts due to its attractive appearance and superior corrosion resistance properties. It is obtained by electrodeposition via a conventional bath with hexavalent $\mathrm{Cr}$ ions. This manufacturing technique has many drawbacks, such as very low efficiency and high operating temperature and it is hazardous to health. In this work, we studied a $\mathrm{Cr}-\mathrm{Ni}$ alloy deposition technique and compared the alloy coating properties to those with conventional Cr coating. Sequential two-step alloy electrodeposition was also compared. We took varying concentrations of $\mathrm{Cr}$, $\mathrm{Ni}$ and complexing agents for the electrodeposition of $\mathrm{Cr}-\mathrm{Ni}$ alloy and sequential $\mathrm{Cr}-\mathrm{Ni}$ alloy coating on mild steel. Operating parameters, i.e. current density and temperature, were varied to examine their effects on the coating properties. The coatings thus obtained were characterized by visual observation, corrosion test, microhardness measurement, morphology and chemical analysis. The $\mathrm{Cr}-\mathrm{Ni}$ alloy coating was found to be more corrosion resistant in $5 \% \mathrm{NaCl}$ solution and harder than the pure $\mathrm{Cr}$ coating obtained by conventional electrodeposition. Toxic gas was produced in a much lower extent in the alloy coating than the conventional $\mathrm{Cr}$ coating technique. Again, the two-step $\mathrm{Cr}-\mathrm{Ni}$ alloy coating was found better in terms of corrosion resistance as well as hardness compared to the $\mathrm{Cr}-\mathrm{Ni}$ alloy coating. The process was also found to be much more environmentally friendly.
\end{abstract}

Keywords: Alloy electrodeposition; conventional $\mathrm{Cr}$ coating; sequential coating; corrosion; hardness.

\section{INTRODUCTION}

The development of metal/alloy deposits is of great interest as it provides an economic alternative to thermally produced alloys (Chisholm et al., 1988; Ueda et al, 2004). Thus it would be highly desirable for deposit alloy coatings on a cheap substrate to impart their favorable properties to the base metal. Steels are the dominant constructional materials in coastal structures, and are subjected to corrosion in seawater containing a reasonable $\%$ of $\mathrm{NaCl}$. So far, the development of different coatings on steel through electrodeposition has been investigated, such as $\mathrm{Zn}$ coating, Ni coating and $\mathrm{Cr}$ coating, and they appeared to provide corrosion resistance to various degrees in air and a range of gaseous environments (Moniruzzaman and Roy, 2011; Ou et al., 2008; Steffani et al., 1997; Trethewey and Chamberlain, 1995). Electrodeposited $\mathrm{Cr}$ is widely used as the outer surface of precision parts due to its attractive appearance and superior corrosion resistance (Brooman, 1994; El-Sharif et al., 1999; Brooman et al., 1994). Until now, Cr deposits were commonly obtained using an electroplating bath with hexavalent $\mathrm{Cr}$ ions. 
However, researchers are now looking for alternative coatings since using hexavalent $\mathrm{Cr}$ ion baths has many disadvantages, such as a low cathode current efficiency, high operating temperature and being harmful to human health and the environment. The need for alternative surface coatings to replace conventional $\mathrm{Cr}$ coating from toxic hexavalent $\mathrm{Cr}$ baths has attracted great attention in recent years (Harris et al., 1995; McDougall et al., 1998; Song and Chin, 2002). Thus instead of using only Cr coating, $\mathrm{Cr}-\mathrm{Ni}$ alloy coating has been applied on steel by thermal spray techniques and studies have been carried out on its hot corrosion behavior at $400^{\circ} \mathrm{C}$ in air and in air containing $\mathrm{SO}_{3}$ (Ou et al., 2008). Corrosion resistance was found to increase on application of $\mathrm{Cr}$ $\mathrm{Ni}$ coating. However, studies on the corrosion behavior of $\mathrm{Cr}-\mathrm{Ni}$ coated steel in aqueous $\mathrm{NaCl}$ solution (coastal environments) are limited. Moreover, reports are not readily available on the development of $\mathrm{Cr}-\mathrm{Ni}$ coating on steel by electrodeposition and its effect on corrosion behavior in coastal environments. Huang et al. (2009) studied $\mathrm{Cr}-\mathrm{Ni}$ alloy deposition in a trivalent $\mathrm{Cr}$-based bath. In the present work, we study $\mathrm{Cr}-\mathrm{Ni}$ alloy electrodeposition from an environmentally non-toxic trivalent $\mathrm{Cr}$ bath that is different from the baths previously used. The hardness, corrosion resistance, chemical composition and morphology of the coating are tested and compared with those of a conventional $\mathrm{Cr}$ coating. Two-step sequential electrodeposition techniques are compared in this study.

\section{EXPERIMENTAL}

A mild steel sheet of $2 \mathrm{~mm}$ thickness was taken, and specimens were made as per the desired dimensions by cutting in a machine cutter. The specimens' surface was cleaned with detergent, made rust free by pickling in $20 \%$ hot $\mathrm{HCl}$ solution and washed by rinsing with deionized water. Three different baths with different compositions were used for $\mathrm{Cr}-\mathrm{Ni}$ alloy coatings. The bath contents and their concentrations are given in Table 1. Only one bath produced good alloy coatings. Thus the other two alloy baths were discarded.

Table 1. Bath compositions for Cr-Ni alloy coating

\begin{tabular}{|c|c|c|}
\hline Bath identification & Bath composition $(\mathrm{g} / \mathrm{l})$ & Coating appearance \\
\hline \multirow{3}{*}{ Bath X } & $\mathrm{CrCl}_{3} \cdot 6 \mathrm{H}_{2} \mathrm{O}: 213$ & \multirow{3}{*}{ Bad } \\
\hline & $\mathrm{NiSO}_{4} \cdot 6 \mathrm{H}_{2} \mathrm{O}: 53$ & \\
\hline & Urea & \\
\hline \multirow{3}{*}{ Bath Y } & $\mathrm{CrCl}_{3} \cdot 6 \mathrm{H}_{2} \mathrm{O} \quad: 213$ & \multirow{3}{*}{ Bad } \\
\hline & $\mathrm{NiSO}_{4} \cdot 6 \mathrm{H}_{2} \mathrm{O}: 106$ & \\
\hline & Urea & \\
\hline \multirow{3}{*}{ Bath Z } & $\mathrm{CrCl}_{3} \cdot 6 \mathrm{H}_{2} \mathrm{O}$ & \multirow{3}{*}{ Good } \\
\hline & $\mathrm{NiCl}_{2} \cdot 6 \mathrm{H}_{2} \mathrm{O}$ & \\
\hline & Urea & \\
\hline
\end{tabular}

The bath producing the good alloy coating, baths for pure $\mathrm{Cr}$ and $\mathrm{Ni}$ coatings and sequential $\mathrm{Cr}-\mathrm{Ni}$ alloy coating as well as the operating parameters used are summarized in Table 2. The coating appearance was first observed by naked eye. Uniform coatings with good appearance were selected for further study. The corrosion of the coatings was evaluated by the salt immersion test. The coated samples were weighed and recorded before the test commenced and then immersed in freshly 
prepared 5\% $\mathrm{NaCl}$ solution. The samples were kept immersed for 6 hours and then taken out of the solution. After rinsing with water and drying with acetone, the weight of the samples was taken again. The corrosion media and time $(5 \% \mathrm{NaCl}$ solution, 6 hours) was selected by previous experiments so that corrosion was limited to the coating and did not attack the substrate. The coating was partially dissolved in $5 \% \mathrm{NaCl}$ solution and thus the final weight was less than the initial weight in every case. The difference in weight of the sample before and after immersion (weight loss) was considered as the index of corrosion and was expressed as $\mathrm{mdd}\left(\mathrm{mg} / \mathrm{dm}^{2} / \mathrm{day}\right)$. The microstructure of the surface coating was observed by Scanning Electron Microscopy (SEM), and the coating composition was analyzed by Energy Dispersive X-ray (EDX). The microhardness of the coating was measured using a Shimadzu Microhardness Tester applying a load of $25 \mathrm{~g}$ for 10 seconds. Coating thickness was measured by observing a cross-sectional view under SEM. Finally the measured properties of the Cr$\mathrm{Ni}$ alloy coating were compared with those of the pure $\mathrm{Cr}$ and pure Ni coatings.

Table 2. Bath compositions and operating parameters for pure $\mathrm{Cr}$, pure $\mathrm{Ni}, \mathrm{Cr}-\mathrm{Ni}$ alloy and two-step sequential alloy coatings

\begin{tabular}{|c|c|c|c|c|c|}
\hline \multicolumn{2}{|c|}{$\begin{array}{l}\text { Coating Composition } \\
\qquad(\mathrm{g} / \mathrm{l})\end{array}$} & $\begin{array}{l}\text { Current density } \\
\qquad\left(\mathrm{A} / \mathrm{dm}^{2}\right)\end{array}$ & \multirow{2}{*}{$\begin{array}{c}\text { Temperature } \\
\left({ }^{\circ} \mathrm{C}\right)\end{array}$} & \multirow[t]{2}{*}{$\begin{array}{c}\text { Voltage } \\
(\mathrm{V})\end{array}$} & \multirow[t]{2}{*}{$\begin{array}{l}\text { Holding Time } \\
\quad \text { (minute) }\end{array}$} \\
\hline & & Pure & & & \\
\hline $\begin{array}{l}\mathrm{CrO}_{3} \\
\mathrm{H}_{2} \mathrm{SO}_{4}\end{array}$ & $\begin{array}{l}: 225 \\
: 2.25\end{array}$ & $\begin{array}{c}5 \\
5.5 \\
7 \\
9 \\
\end{array}$ & 50 & 10 & 10 \\
\hline \multicolumn{6}{|c|}{ Pure Ni coating } \\
\hline $\begin{array}{l}\mathrm{NiSO}_{4} \\
\mathrm{NiCl}_{2} \\
\mathrm{H}_{3} \mathrm{BO}_{3}\end{array}$ & $\begin{array}{l}: 270 \\
: 40 \\
: 24.33\end{array}$ & $\begin{array}{c}2 \\
4 \\
5 \\
5.5\end{array}$ & 55 & 20 & 10 \\
\hline \multicolumn{6}{|c|}{ Cr-Ni alloy coating } \\
\hline $\begin{array}{l}\mathrm{CrCl}_{3} \cdot 6 \mathrm{H}_{2} \mathrm{O} \\
\mathrm{NiCl}_{2} \cdot 6 \mathrm{H}_{2} \mathrm{O} \\
\text { Urea }\end{array}$ & $\begin{array}{l}: 213 \\
: 95 \\
: 120\end{array}$ & $\begin{array}{l}10 \\
20 \\
30 \\
40\end{array}$ & 35 & 30 & 10 \\
\hline \multicolumn{6}{|c|}{ Sequential Cr-Ni alloy coating } \\
\hline $\begin{array}{l}\mathrm{CrCl}_{3} \cdot 6 \mathrm{H}_{2} \mathrm{O} \\
\mathrm{NiCl}_{2} \cdot 6 \mathrm{H}_{2} \mathrm{O} \\
\text { Urea }\end{array}$ & $\begin{array}{l}: 213 \\
: 95 \\
: 120\end{array}$ & 10 then 30 & 35 & 30 & 10 then 5 \\
\hline
\end{tabular}




\section{RESULTS AND DISCUSSION}

\section{Appearance of the Coatings}

Pure $\mathrm{Cr}$ coating and $\mathrm{Cr}-\mathrm{Ni}$ alloy coating with good appearances and one bad $\mathrm{Cr}-\mathrm{Ni}$ alloy coating are shown in Figure 1. Only the acceptable coatings were further studied for their properties.

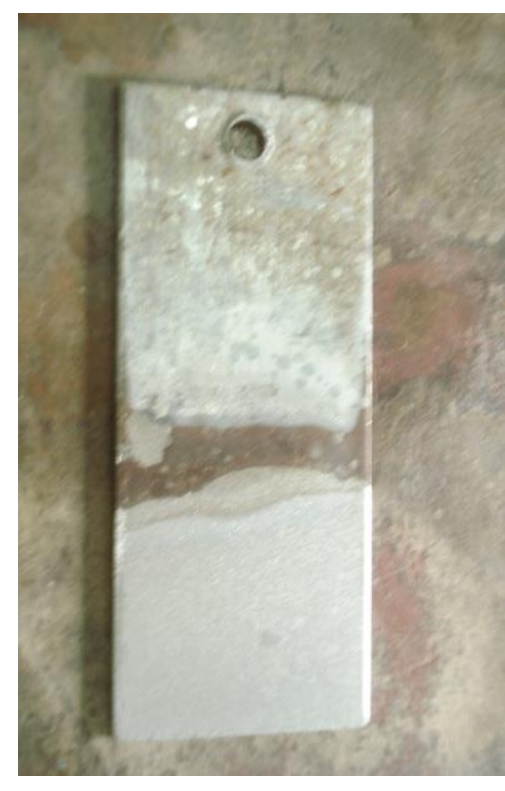

(a)

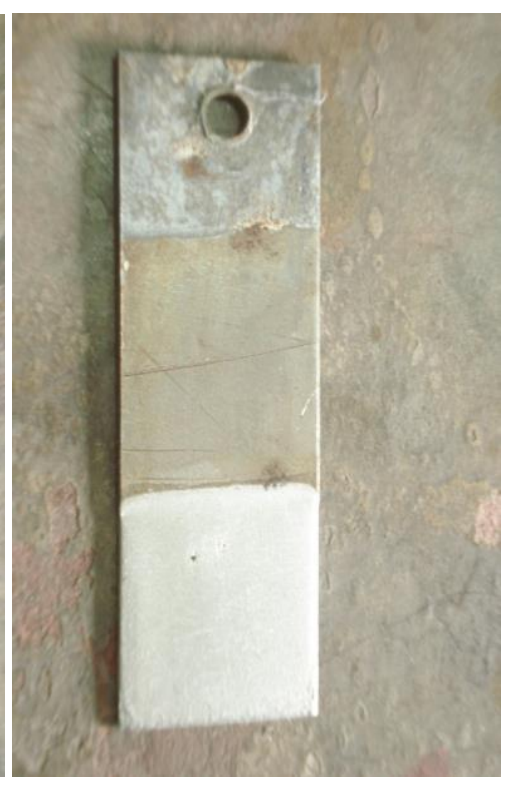

(b)

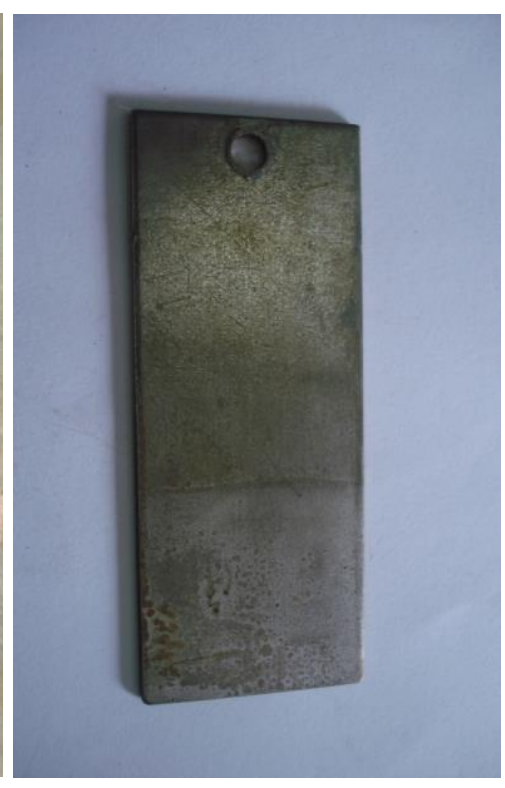

(c)

Figure 1. (a) Pure Cr coating (b) Cr-Ni alloy coating with good appearances and (c) bad Cr-Ni alloy coating.

\section{Chemical Composition of Cr-Ni Alloy Coatings}

The Cr-Ni coating composition was analyzed by Energy Dispersive X-ray (EDX). Current density has a profound effect on the coating composition. $\% \mathrm{Cr}$ or $\% \mathrm{Ni}$ in the deposit as a function of the applied current density is shown in Figure 2. Cr content in the deposit increased with current density. A lower current density produced a Ni-rich coating, whereas the Cr-rich coating was produced in the higher current density range. The slope of the curve is not uniform over the experimental current density range of 10$40 \mathrm{~A} / \mathrm{dm}^{2}$. The slope is much steeper in the middle range of $20-30 \mathrm{~A} / \mathrm{dm}^{2}$. Figure 3 shows the EDX spectrum of the Ni-rich coating under an applied current density of 10 $\mathrm{A} / \mathrm{dm}^{2}$. The composition of the Ni-rich alloy coating and the Cr-rich alloy coating produced by the two-step sequential coating technique is also shown in Figure 3 . The two-step sequential coating technique is performed under an applied current density of $10 \mathrm{~A} / \mathrm{dm}^{2}$ for 10 minutes to obtain a Ni-rich alloy deposit, and then with a current density of $30 \mathrm{~A} / \mathrm{dm}^{2}$ for 5 minutes to obtain a Cr-rich alloy deposit. The appearance of a small amount of $\mathrm{C}$ in the coating is assumed to come from the underlying steel substrate. 


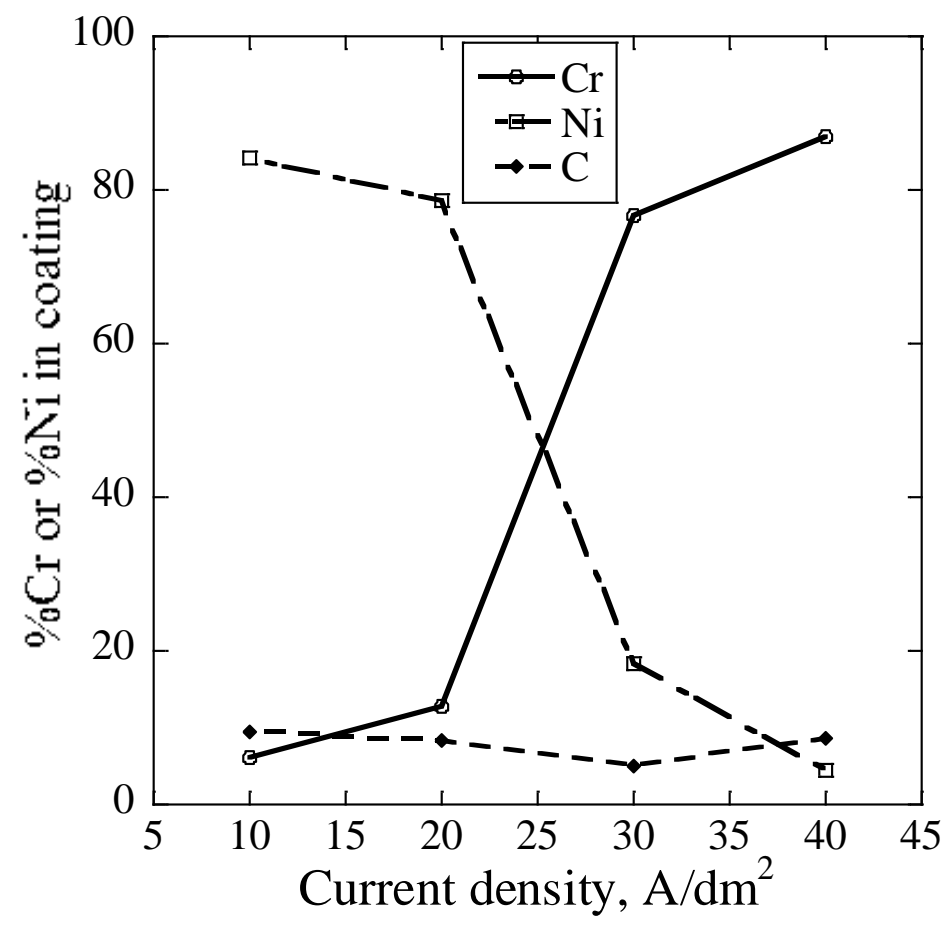

Figure 2. Effect of current density on the chemical composition $\mathrm{Cr}-\mathrm{Ni}$ alloy coating.

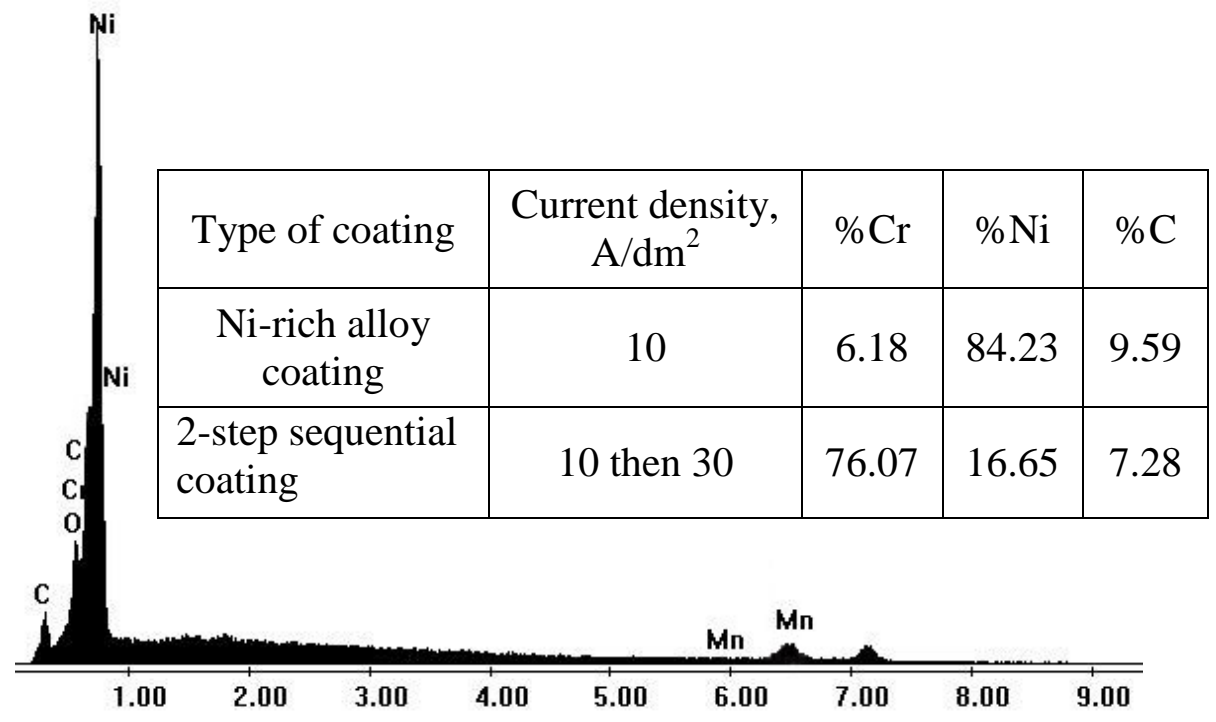

Figure 3. EDX spectrum of Ni-rich coating under applied current density of $10 \mathrm{~A} / \mathrm{dm}^{2}$. The inset table shows $\mathrm{Ni}$-rich coating composition and $\mathrm{Cr}$-rich coating composition produced by two-step sequential technique.

\section{Corrosion Properties of the Coating}

The Salt Immersion Corrosion Test was adopted to measure the corrosion resistance of the electroplated alloy coating. The corrosion of the coatings under various conditions is shown in Figure 4. Pure $\mathrm{Cr}$ and pure Ni coatings were also tested for comparison. 
Results show that the corrosion of alloy coatings in the immersion test is lower than that of either $\mathrm{Cr}$ or $\mathrm{Ni}$ coatings alone. Corrosion is the lowest in the case of the Cr-rich coating deposited by the two-step sequential process. The lowest corrosion of the sequential $\mathrm{Cr}-\mathrm{Ni}$ coating is assumed to be the additional attribution provided by the improved corrosion resistance of the underlying Ni-rich alloy coating deposited at 10 $\mathrm{A} / \mathrm{dm}^{2}$ for 10 minutes. Huang et al. (2009) have shown that the underlying Ni-rich alloy coating helps reduce through-deposit cracking, possibly due to the Ni-rich alloy deposit's softness and lack of cracks (Figure 5).

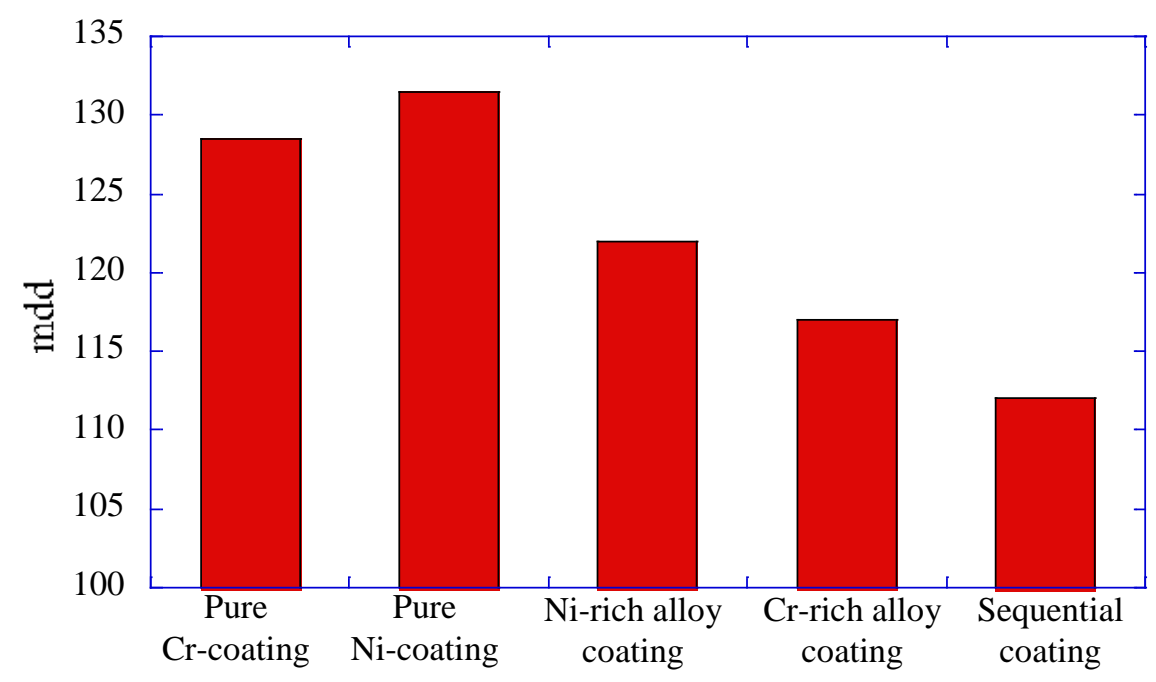

Figure 4. Corrosion of metal and alloy coatings under various conditions.

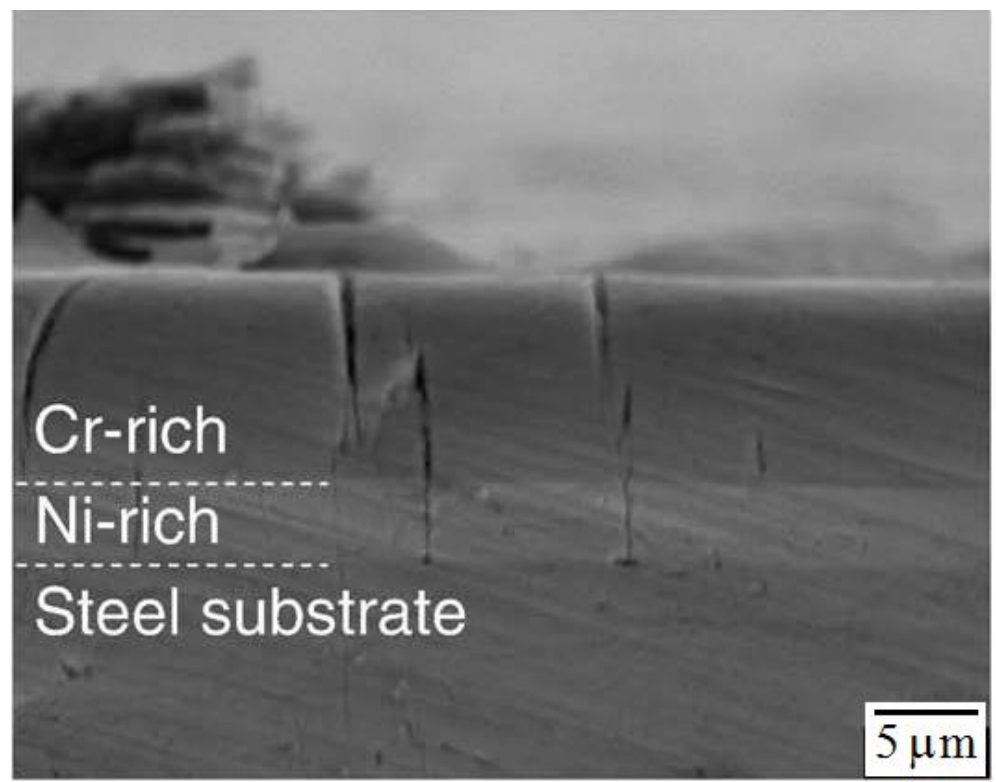

Figure 5. Cross-sectional micrograph of sequential Cr-Ni alloy coating (Huang et al., 2009). 


\section{Microhardness of Coatings}

During the microhardness testing of the coating, special care was taken so that in all cases the depth of indentation was less than one-fifth of the coating thickness, in order to eliminate the effect of the substrate's properties. Earlier, the coating thickness was measured from the cross-section of the coated sample and the thickness for Cr-Ni alloy coating was found to be about $15 \mu \mathrm{m}$. A cross-sectional view of an etched coated sample is shown in Figure 6. Figure 7 shows the microhardness of the various metal and alloy coatings undertaken in this study. The microhardness of the $\mathrm{Cr}-\mathrm{Ni}$ alloy coating is seen to be higher than either the pure $\mathrm{Cr}$ or $\mathrm{Ni}$ coatings. Cr-rich sequential alloy coating possesses the highest value of microhardness.

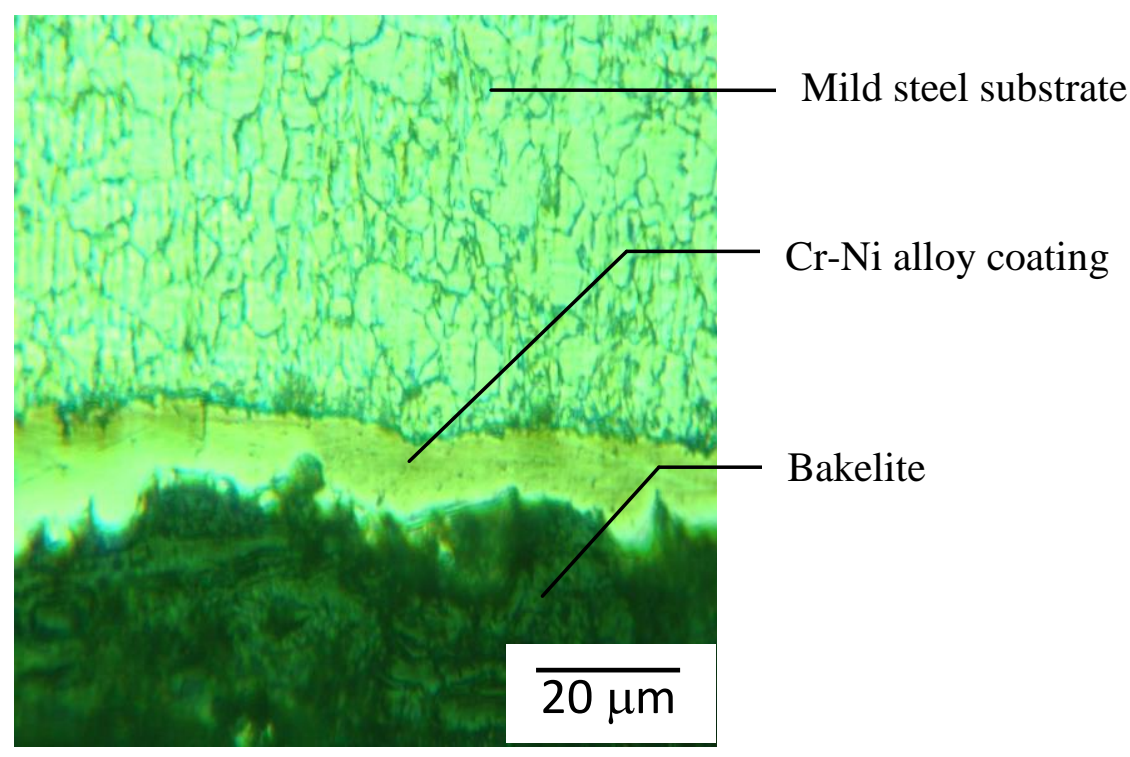

Figure 6. Cross-sectional view of an etched coated sample.

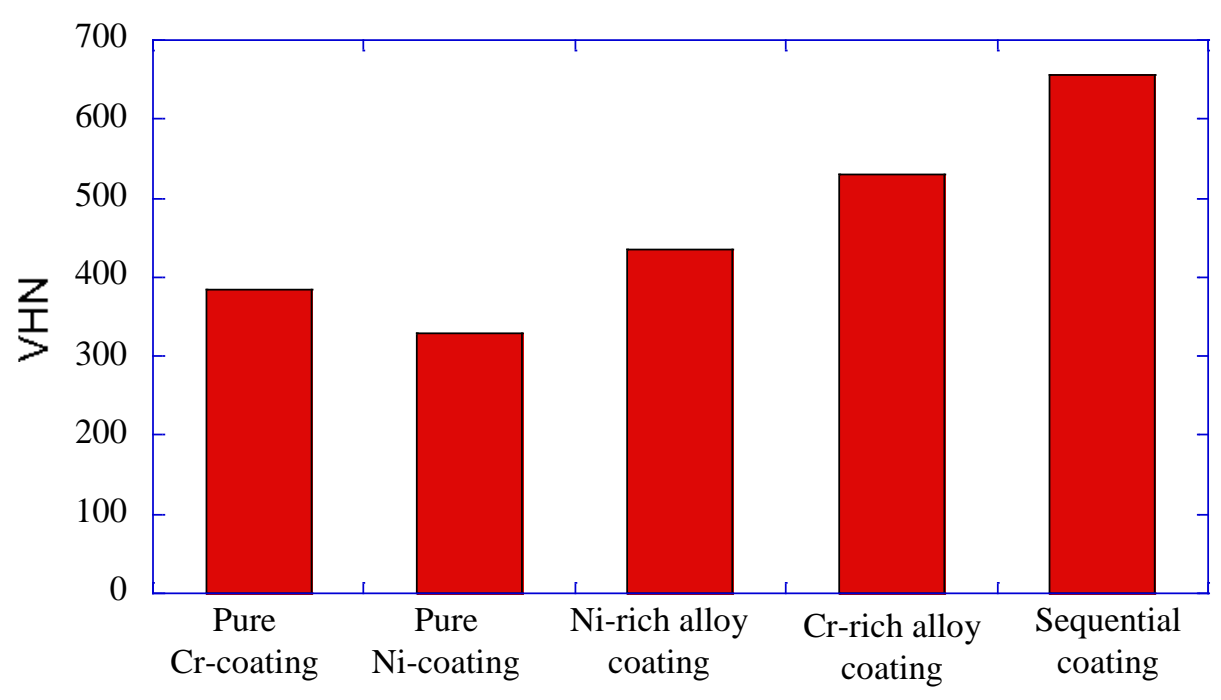

Figure 7. Microhardness of metal and alloy coatings under various conditions. 


\section{Surface Morphology of the Coating}

The surface morphology was studied by Scanning Electron Microscopy (SEM). Figure 8 shows the morphology of various coatings. The surface of the alloy coatings (Figures 8(b)-(d)) seems to consist of fine globules. A non-uniform surface level is observed in the pure Cr coating (Figure 8(a)). Thus the higher value of hardness data for the $\mathrm{Cr}-\mathrm{Ni}$ alloy coating than the pure $\mathrm{Cr}$ coating is consistent with their difference in surface morphology.

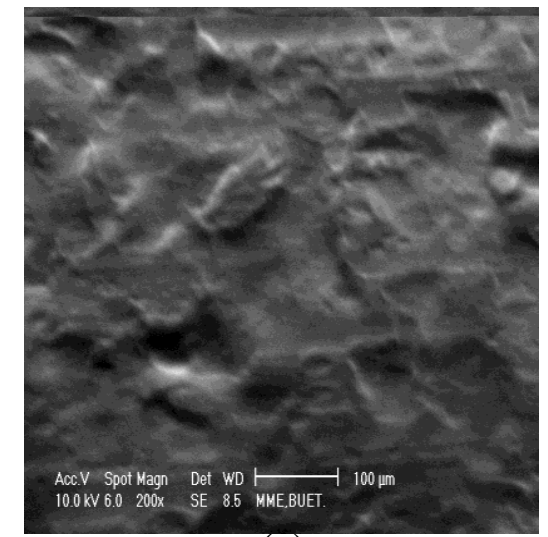

(a)

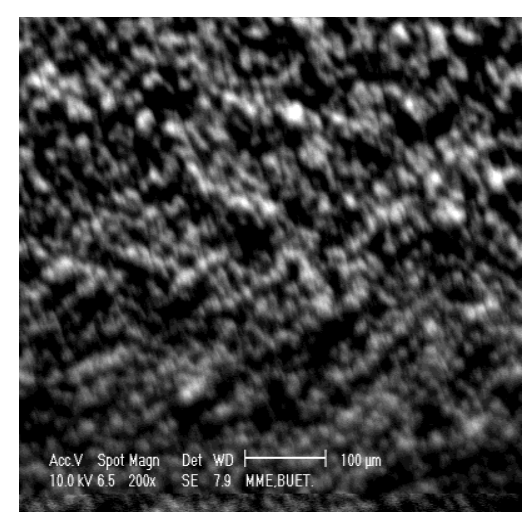

(c)

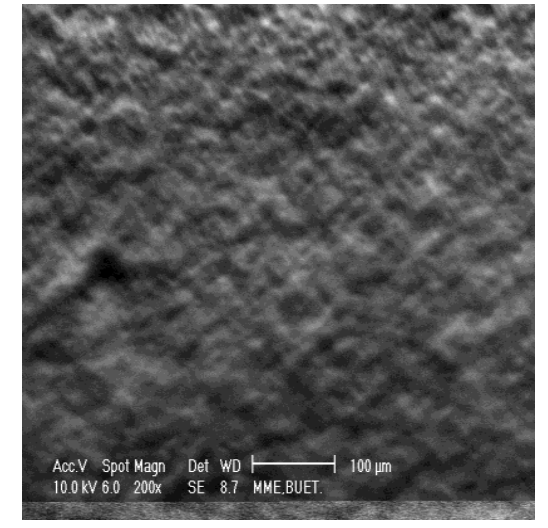

(b)

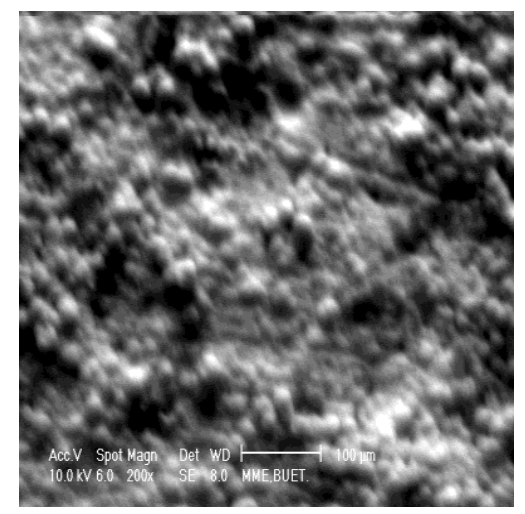

(d)

Figure 8. Surface morphology of (a) pure Cr coating, (b) Ni-rich alloy coating, (c) Crrich alloy coating and (d) sequential Cr-rich alloy coating

\section{CONCLUSION}

Cr-Ni alloy electrodeposition was studied in order to overcome the demerits of the conventional $\mathrm{Cr}$ electrodeposition process. An electrodeposited $\mathrm{Cr}-\mathrm{Ni}$ alloy coating on a mild steel substrate was tested for its compatibility with pure $\mathrm{Cr}$ coating. The following conclusions were drawn.

i) Uniform and bright $\mathrm{Cr}-\mathrm{Ni}$ alloy as well as the sequential $\mathrm{Cr}-\mathrm{Ni}$ coating could be electrodeposited from a bath containing $213 \mathrm{~g} / 1 \mathrm{CrCl}_{3} \cdot 6 \mathrm{H}_{2} \mathrm{O}, 95 \mathrm{~g} / 1 \mathrm{NiCl}_{2} \cdot 6 \mathrm{H}_{2} \mathrm{O}$ and $120 \mathrm{~g} / \mathrm{l}$ urea. 
ii) The lower current density range of $10-20 \mathrm{~A} / \mathrm{dm}^{2}$ produced a Ni-rich coating, whereas a Cr-rich coating was produced in the higher current density range of $30-40 \mathrm{~A} / \mathrm{dm}^{2}$.

iii) $\mathrm{Cr}-\mathrm{Ni}$ alloy coating is more corrosion resistant in $5 \% \mathrm{NaCl}$ solution, as well as being harder than the conventional $\mathrm{Cr}$ coating.

iv) The sequential alloy coating (first Ni-rich and then Cr-rich) is harder and more corrosion resistant than the $\mathrm{Cr}-\mathrm{Ni}$ alloy coating. This coating has the optimum properties among all those studied in the present work.

v) The sequential Cr-Ni alloy coating might be a replacement for the conventional toxic and inefficient $\mathrm{Cr}$ coating process.

\section{REFERENCES}

Brooman, E.W. 1994. Chromium alloy plating. Metals Handbook. Ohai: ASM.

Chisholm, C.U., El-Sharif, M. and Watson, A. 1988. The sustained deposition of thick coatings of $\mathrm{Cr}-\mathrm{Ni}$ and $\mathrm{Cr}-\mathrm{Ni}-\mathrm{Fe}$ alloys and their properties. Transactions of the Institute of Metal Finishing, 66: 34-40.

El-Sharif, M., McDougall, J. and Chisholm, C.U. 1999. Electrodeposition of thick chromium coatings from a chromium (III) - glycine complex. Transactions of the Institute of Metal Finishing, 77(4): 139-144.

Harris, T.M., Whitney, G.M. and Croll, I.M. 1995.The electrodeposition of Ni-Fe-Cr alloys for magnetic thin film applications. Journal of the Electrochemical Society, 142(4): 1031-1035.

Huang, C.A., Lin, C.K. and Chen, C.Y. 2009. Hardness variation and corrosion behavior of as-plated and annealed $\mathrm{Cr}-\mathrm{Ni}$ alloy deposits electroplated in a trivalent chromium-based bath. Journal of Surface Coating Technology, 203: 3686-3691.

McDougall, J., El-Sharif, M. and Ma, S. 1998. Chromium electrodeposition using a chromium (III) glycine complex. Journal of Applied Electrochemistry, 28: 929934.

Moniruzzaman, M. and Roy, S. 2011. Effect of pH on electroless Ni-P coatings of conductive and nonconductive materials. International Journal of Automotive and Mechanical Engineering, 4: 481-489.

Ou, X. M., Sun, Z., Sun, M. and Zou, D.L. 2008. Hot-corrosion mechanism of Ni-Cr coatings at $650^{\circ} \mathrm{C}$ under different simulated corrosion. conditions. Journal of China University of Mining and Technology, 18(3): 444-448.

Song, Y.B. and Chin, D.T. 2002. Current efficiency and polarization behavior of trivalent chromium electrodeposition process. Electrochimica Acta, 48(4): 349356.

Steffani, C.P., Dini, J.W., Groza, J.R. andPalazoglu, A. 1997: Electrodeposition and corrosion resistance of Ni-W-B coatings. Journal of Materials Engineering and Performance, 6(4): 413-416.

Trethewey, K.R. and Chamberlain, J. 1995. Corrosion for science and engineering. 2nd ed. USA: NACE International.

Ueda, M., Susukida, D., Konda, S. and Ohtsuka, T. 2004. Improvement of resistance of TiAl alloy against high temperature oxidation by electroplating in $\mathrm{AICI}_{3}$-NaCIKCI-CrCl ${ }_{2}$ molten salt. Journal of Surface Coating Technology, 176(2): 202-208. 